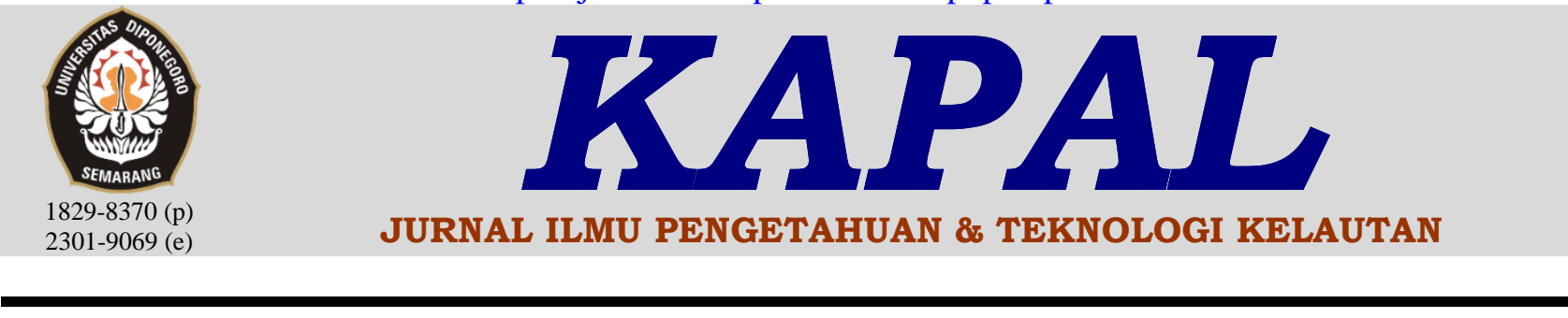

\title{
Pemodelan Sistem Kontrol Exhaust Fan Terintegrasi Gas Detector CO Pada Kamar Pompa (Pump Room) Kapal Tanker
}

\author{
Indra Ferdiansyah ${ }^{\left.l)^{*}\right)}$, Dirhamsyah ${ }^{2}$, Ardiansyah ${ }^{2)}$ \\ ${ }^{1)}$ Elektro, Elektro Pelayaran, Politeknik Pelayaran Surabaya \\ ${ }^{2)}$ Teknik, Teknika Pelayaran, Politeknik Pelayaran Surabaya \\ Jl. Gunung Anyar Boulevard No 1 Surabaya, Kampus II Politenik Pelayaran Surabaya, Indonesia 60294
}

\begin{abstract}
Abstrak
Udara bersih dalam sebuah ruangan tertutup menjadi hal penting yang harus diperhatikan. Terutama terhadap aktifitas yang akan dilakukan di dalam ruangan tersebut. Seperti halnya dalam sebuah kamar pompa pada kapal tanker minyak perlu mendapatkan perhatian khusus. Pompa yang digunakan untuk memidahkan cairan ke suatu tempat tertentu yang memungkinkan terjadi kebocoran sehingga mengakibatkan udara dalam ruangan tersebut terkomtaminasi kandungan gas yang membahayakan. Exhaust fan dengan type ceiling mount menjadi alternatif yang dapat digunakan untuk melakukan sirkulasi udara bersih dengan membuang udara kotor dalam ruangan tersebut. Dengan mengintegrasikan sebuah sensor gas TGS 2600 menjadikan sistem ini sebagai alat bantu keamanan untuk orang yang melakukan aktifitas didalam ruangan kamar pompa. Prinsip kerja dari sistem ini, ketika sensor gas mendeteksi kandungana gas berbahaya maka akan mengintrusikan kontroler untuk menyalakan exhaust fan dan lampu indikator sebagai visualisai keadaan kandungan gas didalam ruangan, semakin tinggi kandungan gasnya semakin terang nyala lampunya sedangkana apabila kandungan gas sudah hilang maka lampu akan redup dan exhaust fan akan mati begitu seterusnya dilakukan secara kontinyu.
\end{abstract}

Copyright $@ 2017$, KAPAL, ISSN:1829-8370

Kata Kunci : Sirkulasi Udara, Kamar Pompa, Exhaust Fan, Sensor Gas, Lampu Indikator

\section{PENDAHULAN}

Kapal tanker ialah kapal yang dirancang untuk mengangkut minyak atau produk turunanya. Jenis utama kapal tanker adalah tanker minyak, tanker kimia dan tanker LNG. Beberapa peralatan pada jenis kapal ini selalu mendapatkan perhatian khusus salah satunya kamar pompa dimana y ang pada umumnya terletak dibagian depan bawah superstructure terpisah dengan kamar mesin. Ruangan ini khusus digunakan untuk cargo pump yang terpisah dengan pompa-pompa lainya, sehingga sistem keamanan/ SOP dibuat secara detail untuk para pekerja yang akan melakukan aktifitas di dalam ruangan tersebut. Bahaya yang utama yang dapat terjadi pada ruangan tersebut adalah terjadinya kebocoran gas sehingga pekerja harus memastikan terlebih dahulu tidak ada

*) Penulis Korespondensi :

Email : ferdi.electricalpe09@gmail.com kandungan gas berbahaya didalam ruangan.

Exhaust fan pada kamar pompa menjadi salah satu solusi utama yaitu suatu peralatan mekanik yang berfungsi untuk menghisap udara pada ruangan kamar pompa kemudian dibuang melalui cerobong diatas kamar pompa / ventilasi udara. Hal demikian perlu dilakukan pada kamar pompa di dalam kapal tanker dikarenakan kemungkinan udara didalamnya tercampur dengan gas berbahaya. Udara bersih dalam kamar pompa menurut standar keselamatan tidak boleh kurang dari $15 \%$ serta harus bebas dari gas-gas beracun agar awak kapal dapat melakukan pekerjaan di ruangan tersebut [1].

Seperti yang telah dibahas dan dijelaskan sebelumnya bahwa di dalam kamar pompa harus selalu terdapat udara bersih agar pekerja tidak mengalami ganguan pada sistem pernafasan. Dengan metode yang diusulkan melalui sistem ventilasi udara menggunakan Exhaust Ean ter- 
Integrasi sensor Gas Detector diharapkan mampu menjaga udara didalam ruangan tersebut agar tetap bersih tidak terkontaminasi kandungan gasgas yang membahayakan para pekerja seperti (CO) atau kandungan gas lainya.

\section{METODE}

\subsection{Blok Diagram Sistem}

Untuk memudahkan pemodelan sistem dibuatlah sebuah blok diagram sebagai berikut:

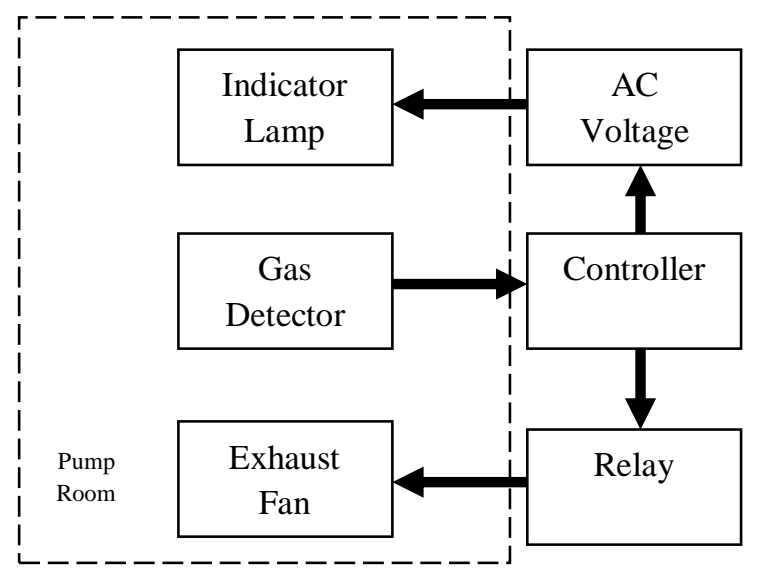

Gambar 1. Blok Diagram Sistem Exhaust Fan

Pump Room Ter-Integrasi Gas Detector

Pada blok diagram diatas diusulkan sebuah sistem kontrol ventilasi udara pada kamar pompa menggunakan exhaust fan yang terintegrasi dengan gas detector. Keterangan gambar blok diagram adalah sebagai berikut:

1. Exhaust Fan : Aktuator yang digunakan untuk membuang kandungan gas berbahaya pada kamar pompa.

2. Gas detector : Sensor untuk mendeteksi kandungan gas berbahaya didalam kamar pompa.

3. Relay : Sebagai saklar exhaust fan yang bekerja secara kontrol konvensional dengan metode elektromagnetik.

4. Indicator Lamp : Sebagai indikator kandungan gas didalam ruanga. Semakin besar kandungan gas maka lampu akan menyala lebih terang begitu sebaliknya.

5. AC Voltage Controller : Sebagai suplai lampu indikator yang dapat diatur melalui Controller.

6. Controller: Sistem yang digunakan untuk memberikan perintah menyalakan exhaust fan ketika terdapat kandungan gas berbahaya terdeteksi oleh sensor dan mematikanya ketika kandungan gas telah bersih.
7. Pump Room : Ruangan yang akan diterapkan sebagai penelitian desain sistem kontrol.

Ilustrasi kerja dari sistem yang diusulkan dilakukan dengan beberapa kondisi yaitu pada kondisi pertama pada ruangan tidak terdapat kandungan gas berbahaya, kondisi kedua sistem mendeteksi adanya kandungan gas berbahaya yang diasumsikan sekitar 30\%, kondisi ketiga sistem mendeteksi kandungan gas berbahaya semakin meningkat menjadi 50\%. Berikut ilustrasi yang diberikan:

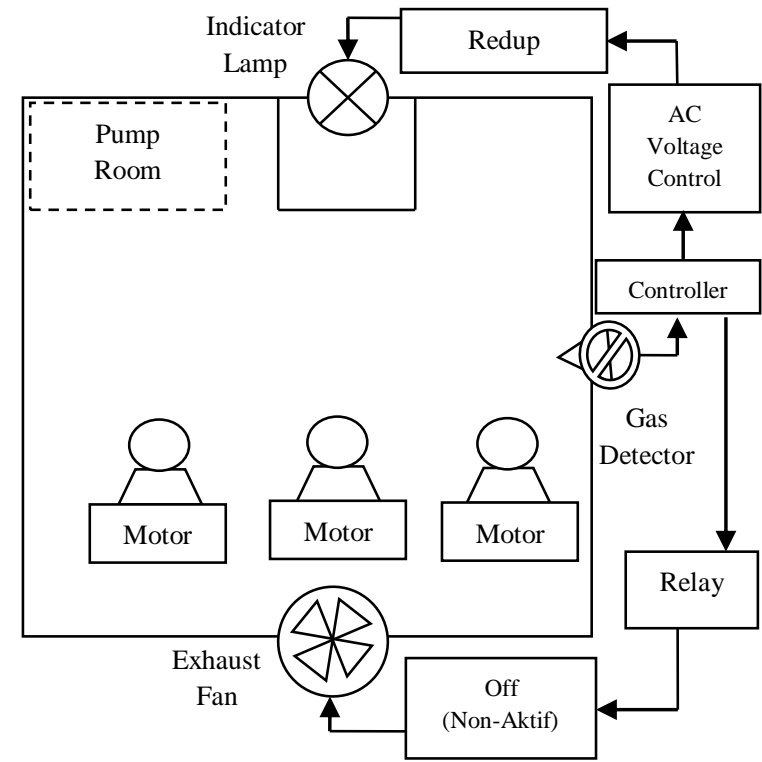

Gambar 2. Ilustrasi 1 kondisi ruangan tanpa kandungan gas berbahaya



Gambar 3. Ilustrasi 2 kondisi ruangan dengan kandungan gas berbahaya $30 \%$ 


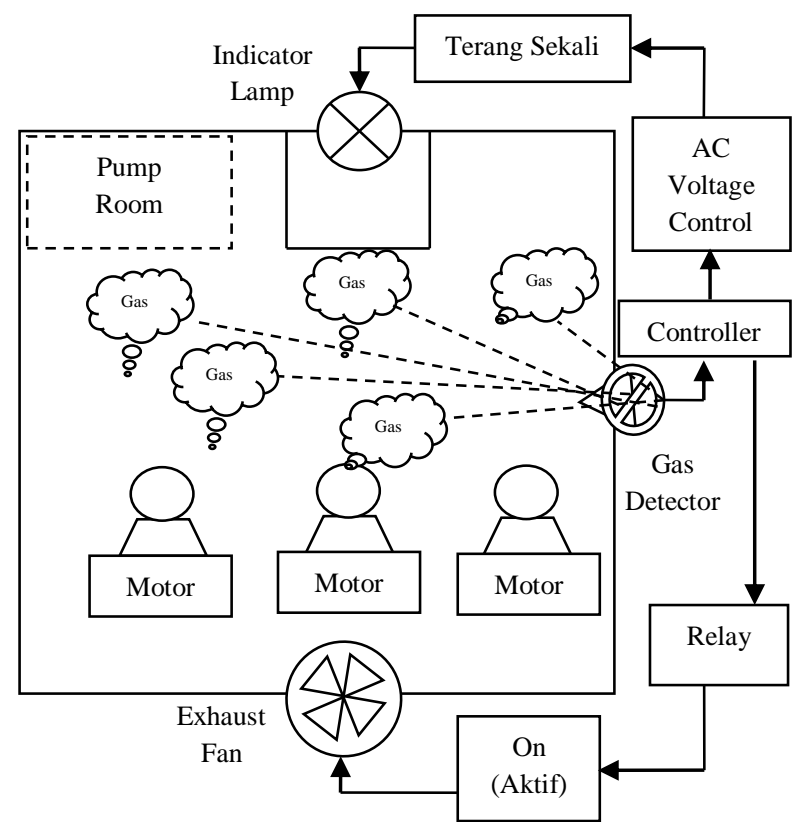

Gambar 4. Ilustrasi 3 kondisi ruangan dengan kandungan gas berbahaya $50 \%$

Dari beberapa ilustrasi diatas dapat diketahui bahwa sistem yang dirancang diharapkan mampu berkontibusi pada Safety Working on Pump Room, dengan penggunaan gas detector sebagai sensor sistem ini akan selalu bekerja ketika mendeteksi ada kandungan gas pada ruangan tersebut. Sensor akan mengirimkan informasi/sinyal terhadap piranti kontrol dalam hal ini mikrokontroller kemudian diproses untuk mengaktifkan exhaust fan serta memberikan lampu indikator kondisi kandungan gas didalam ruangan tersebut. Apabila kandungan gas didalam ruangan tersebut tinggi maka lampu indikator akan menyala terang sekali kemudian bila kandungan gasnya menurun maka lampu indikator akan semakin redup hal demikian dilakukan secara kontinyu sesuai dengan kondisi kandungan gas berbahaya didalamnya.

\subsection{Tahapan Pemodelan}

Tahapan pemodelan sistem yang diusulkan terdiri dari beberapa kegiatan yaitu studi literature untuk melakukan identifikasi masalah, penetuan desain sistem dari permasalahan, pemilihan peralatan dan komponen yang digunakan sesuai sistem yang diterapkan, pembuatan model simulasi, hasil pengujian secara simulasi serta kesimpulan. Untuk memudahkan urutan tahapantahapan berikut maka dibuat kerangka sesuai dengan diagram alir (Flowchart) berikut:

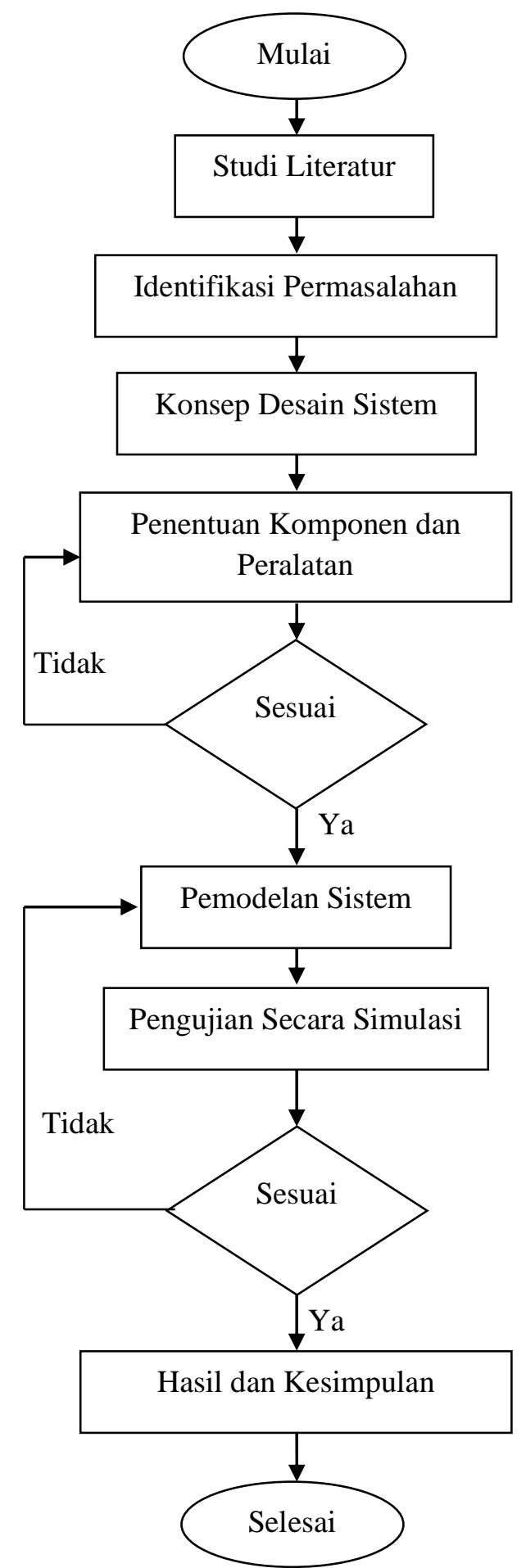

Gambar 5. Diagram alir (Flowchart) sistem yang diusulkan

\subsection{Peralatan yang digunakan}

\subsubsection{Exhaust Fan}

Exhaust fan merupakan salah satuperangkat jenis kipas angin yang saat ini masih banyak digunakan di industry rumahan ataupun dirumah yang mempunyai fungsi penting pada ruangan. Dengan letaknya diantara indoor dan outdoor untuk menjaga sirkulasi udara didalamnya. Dimana, udara panas atau udara kotor didalam 
ruangan dibuang keluar dan saat bersamaan udara sejuk diluar ruangan masuk, sehingga udara selalu berputar agar selalu ada pergantian udara segar dari luar ruangan dan mempunyai sirkulasi udara yang baik[mercubuana]. Tipe exhaust fan yang diusulkan pada pemodelan ini ada dua tipe yaitu Wall Mount dimana pemasanganya dilakukan pada dinding dengan bagian belakang dinding harus berhubungan langsung dengan udara luar untuk pembuangan udara, kemudian tipe Ceiling Mount yang pemasanganya di plafon dengan fungsi melepas udara dari ruangan keluar. Pada tipe ini ada jenis ventilating fan yang dilengkapi pipa penyalur udara keluar. Bentuk fisik dari kedua tipe exhaust fan tersebut ditunjukan pada Gambar 6 dan Gambar 7[2-4].

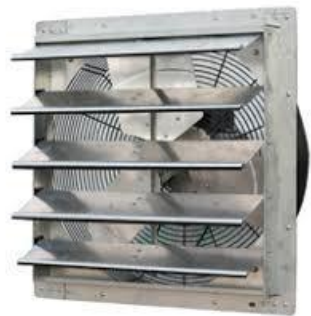

Gambar 6. Bentuk Fisik Exhaust Fan tipe Wall Mount

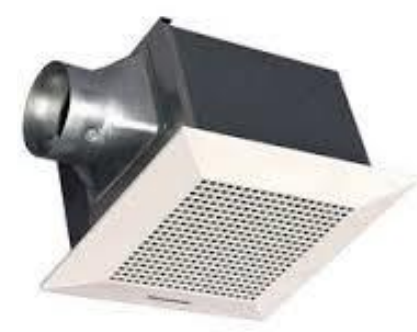

Gambar 7. Bentuk Fisik Exhaust Fan tipe Ceilling Mount

\subsubsection{Sensor Gas}

Sensor secara umum didefinisikan sebagai alat yang mampu menangkap fenomena fisika atau kimia kemudian mengubahnya menjadi sinyal listrik baik arus listrik ataupun tegangan. Fenomena fisik yang mampu menstimulus sensor untuk menghasilkan sinyal elektrik meliputi temperatur, tekanan, gaya, medan magnet, cahaya, dan sebagainya. Sementara fenomena kimia dapat berupa konsentrasi dari bahan kimia baik cairan maupun gas [5].

Figaro TGS 2600 adalah sensor yang digunakan dalam rangkaian ini untuk medeteksi dan mengukur kadar CO. Sensor ini mempunyai nilai resistansi Rs yang akan berubah bila terkena gas dan juga mempunyai sebuah pemanas (heater) yang digunakan untuk membersihkan ruangan sensor dari kontaminasi udara luar. Struktur dari sensor terdapat pada Gambar 8. [datasheet]
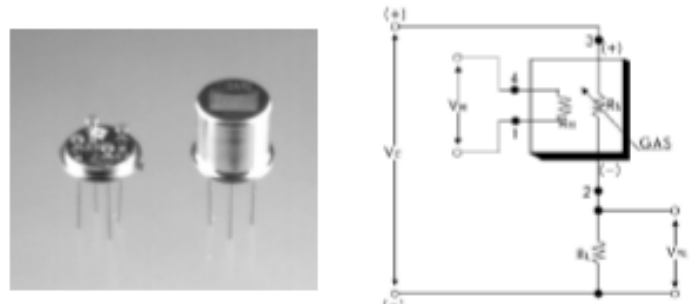

Gambar 8. Bentuk fisik dan struktur elektronik sensor gas TGS 2600

Sensor TGS2600 merupakan salah satu dari sekian banyak sensor gas yang dijual di pasaran. Sensor ini digunakan untuk mendeteksi pencemaran udara, mempunyai sensitivitas tinggi untuk mendeteksi pencemar udara seperti hydrogen dan karbon monoksida (CO) pada konsentrasi yang rendah. Berdasarkan datasheet yang tersedia, sensor ini memiliki karakteristik keluaran yang tidak linier terhadap konsentrasi gas yang dideteksi. Perbandingan perubahan resistansi dengan konsentrasi gas tergambar dalam sebuah kurva dengan skala eksponensial.

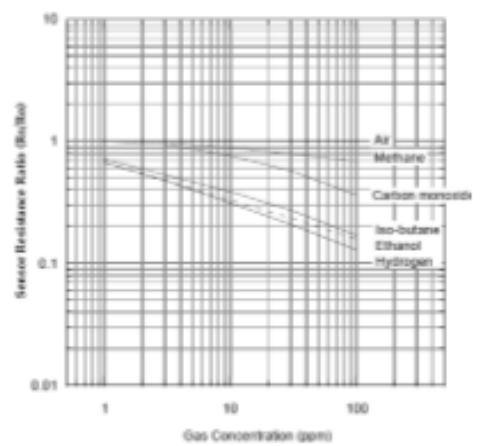

Gambar 9. Karakteristik sensor TGS 2600 terhadap kosentrasi gas

\subsubsection{Lampu Indikator}

Lampu indikator adalah suatu komponen sistem kendali yang berfungsi sebagai pemberi tanda secara vusualisasi terhadap kondisi dari operasi sistem kontrol. Komponen ini memiliki struktur yang terdiri dari sebuah lampu kecil (pijar/neon) dengan rumahnya yang terbuat dari bahan transparan dengan warna-warna tertentu. Lampu indikator umumnya disambungkan dengan sebuah relay sehingga lampu akan menyala seuai dengan prinsip kerja dari sistem yang dirancang. Dalam sistem yang diusulkan nyala lampu akan diatur intensitas cahayanya melalui AC Voltage Control sebagai penanda jumlah kandungan kebocoran gas pada ruangan pump room. Bentuk fisik dari lampu indikator dapat dilihat pada Gambar 10. 


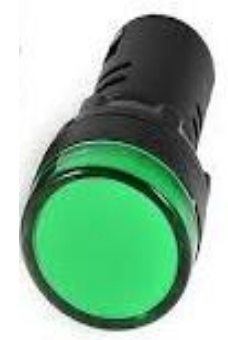

Gambar 10. Bentuk fisik lampu indikator

\subsubsection{Mikrokontroler AT Mega 16}

AVR merupakan seri mikrokontroler CMOS 8-bit buatan Atmel, berbasis arsitektur RISC (Reduced Instruction Set Computer). Hampir semua instruksi dieksekusi dalam satu siklus clock. AVR mempunyai 32 register generalpurpose, timer/counter fleksibel dengan mode compare, interrupt internal dan eksternal, serial USART, programmable Watchdog Timer, dan mode power saving. AVR Mempunyai ADC, PWM internal dan mempunyai In-System Programmable Flash on-chip yang mengijinkan memori program untuk diprogram ulang dalam sistem menggunakan hubungan serial SPI.

AT Mega16 adalah mikrokontroler CMOS 8bit daya-rendah berbasis arsitektur RISC. Beberapa fitur yang dimiliki AVR AT Mega 16 antara lain: [6]

1. Mikrokontroler AVR 8 bit yang memiliki kemampuan tinggi, dengan daya rendah.

2. Arsitektur RISC dengan throughput mencapai 16 MIPS pada frekuensi $16 \mathrm{MHz}$.

3. Memiliki kapasitas Flash memori 16 Kbyte, EEPROM 512 Byte dan SRAM 1 Kbyte.

4. Saluran I/O sebanyak 32 buah, yaitu Port A, Port B, Port C, dan Port D.

5. CPU yang terdiri atas 32 buah register.

6. Unit interupsi internal dan eksternal.

7. Port USART untuk komunikasi serial.

8. Fitur Peripheral yang terdiri dari :

a. Tiga buah Timer/Counter denga kemampuan pembandingan, yaitu :

- 2 buah Timer/Counter 8 bit dengan Prescaler terpisah dan Mode Compare

- 1 buah Timer/Counter 16 bit dengan Prescaler terpisah, Mode Compare, dan Mode Capture

b. Real Time Counter dengan Oscillator tersendiri

c. 4 channel PWM

d. 8 channel, 10-bit ADC, yaitu :

- 8 Single-ended Channel
- 7 Differential Channel hanya kemasan TQFP

- 2 Differential Channel dengan Programmable Gain 1x, 10x atau 200x

e. Byte-oriented Two-wire Serial Interface

f. Programmable Serial USART

g. Antarmuka SPI

h. Watchdog Timer dengan oscillator internal

i. On-chip Analog Comparator

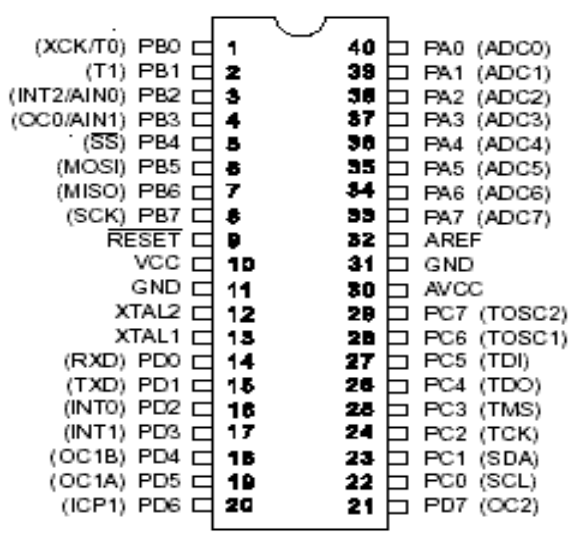

Gambar 11. Pin Atmega16 dalam kemasan 40-pin

\subsection{Pemodelan Sistem menggunakan MATLAB}

Matlab adalah sebuah software yang dapat memudahkana dalam proses simulasi, pada umumya digunakan untuk membuat pemodelan dari sebuah sistem kemudian pemodelan tersebut dilakukan validasi untuk mengetahui hasil respon sistem yang dirancang dalam hal ini sistem kontrol pada kamar pompa untukmendeteksi kandungan gas berbahaya. Pemodelan sistem yang diusulkan ditampilkan pada Gambar 12 .



(a)

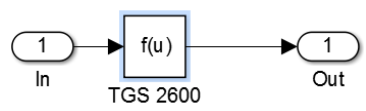

(b)

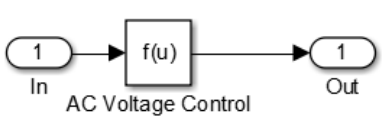

(c)
Gambar 12. (a). Pemodelan sistem exhaust fan (b). Pemodelan sensor gas TGS 2600 (c).

Pemodelan AC Voltage Control untuk suplai lampu indikator 


\section{HASIL DAN PEMBAHASAN}

Proses validasi hasil pemodelan dilakukan secara pengujian simulasi dengan mengintegrasikan ketiga pemodelan yang telah dibuat seperti pada Gambar 13. Pengujian dilakukan untuk mengetahui kinerja exhaust fan ketika mendeteksi kandungan gas, respon sensor gas terhadap besar kandungan gas pada ruangan dan tegangan masukan lampu indikator pada saat sistem bekerja.



Gambar 13. Integrasi Sistem

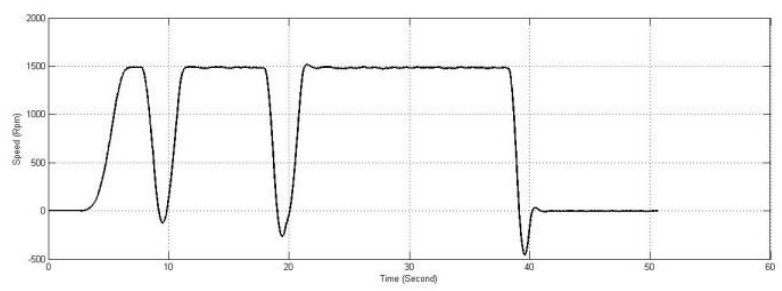

Gambar 14. Respon kinerja exhaust fan pada saat mendeteksi kandungan gas

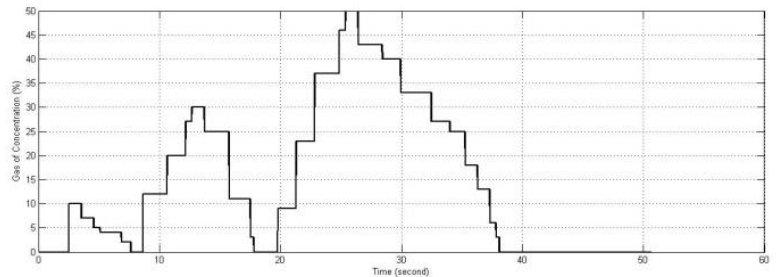

Gambar 15. Respon kinerja sensor gas pada saat mendeteksi kandungan gas

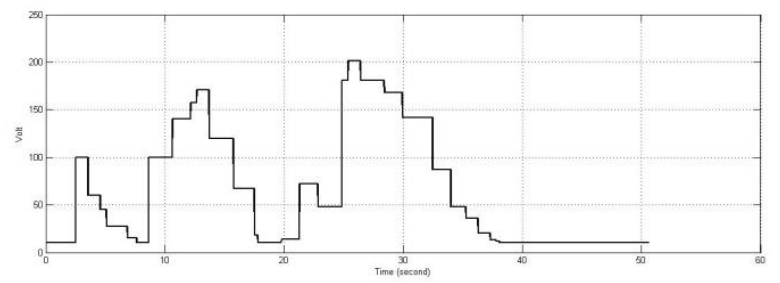

Gambar 16. Respon tegangan untuk pennyalaan

lampu indikator sesuai besar kandungan gas

Dari hasil respon sistem diatas dapat diketahui bahwa pemodelan dapat memberikan kinerja yang baik. Hal tersebut dapat dilihat pada
Gambar 15, ketika sensor gas mendeteksi kandungan gas berbahaya yaitu pada waktu 5 detik pada saat itu juga exhaust fan akan otomatis menyala untuk membuang kandungan gasnya seperti yang ditunjukan pada Gambar 14, dan secara bersamaan lampu indikator menyala dengan tegangangan masukan sesuai dengan besar kandungan gas yang terdeteksi oleh sensor seperti yang ditunjukan pada Gambar 16, semakin besar kandungan gasnya semakin besar tegangan masukan lampu indikator sehingga lampu menyala terang. Sebaliknya apabila kandungan gasnya menurun maka teganganya akan kecil sehingga lampu akan meredup.

Kondisi selanjutnya yaitu pada waktu 7.5 detik kandungan gasnya mulai hilang sehingga dengan otomatis exhaust fan dan lampu indikator akan mati yang menunjukan bahwa sudah tidak ada kandungan gas berbahaya dalam ruangan. Proses tersebut, dilakukan secara kontinyu guna memberikan keamanan dan kenyamanan pada pekerja yang akan melakukan aktifitas pada pump room serta dapat membantu memudahkan proses monitoring secara visual terhadap besar kandungan gas didalam ruangan.

\section{KESIMPULAN}

Berdasarkan hasil validasi pengujian secara simulasi dapat disimpulkan bahwa sistem yang diusulkan mampu memberikan keamanan pada pekerja didalam ruangan pompa. Dengan penerapan sistem otomatisasi pada pembuangan gas berbahaya yang dilengkapi dengan sensor gas dan lampu indikator memudahkan pekerja untuk mengamati seberapa besar kandungan gas didalam ruangan tersebut. Apabila kandungan gas masih tetap tinggi meskipun exhaust fan sudah menyala maka lampu akan terus semakin terang dengan demikian para pekerja harus segera meninggalkan ruangan untuk menjaga keselamatan diri. Dari hal tersebut maka penggunaan Exhaust fan memiliki unsur penting dalam membuang kandungan gas berbahaya didalam ruangan, sehingga diperlukan sistem kontrol yang memiliki respon cepat dan tanggap untuk meminimalisasi kecelakaan kerja akibat adanya kandungan gas berbahaya didalam ruangan.

\section{UCAPAN TERIMA KASIH}

Penulis ucapkan terimakasih kepada tim ERC (Elektro Reseacrh Community) Politeknik Pelayaran Surabaya yang selalu memberikan waktu dan tenaga guna kelancaran selama proses penelitian ini dilakukan. Semoga ERC semakin jaya dapat menjadi wadah bagi peniliti dibidang 
elektro dan selalu ditunggu hasil karya penelitianya untuk Indonesia tercinta.

\section{DAFTAR PUSTAKA}

[1] Wahyu A.N, "IMO Resolution A.1050(27), "Rekomendasi untuk Memasuki Ruangan Tertutup," 2011.

[2] P. K. Colbert, H. Listiana N, A. Jabbar, M. Rambe, "Analisis Perancangan Sistem Ventilasi Dalam Meningkatkan Kenyamanan Termal Pekerja di Ruang Formulasi PT XYZ," e-Jurnal Teknik Industri FT USU, vol. 1, no. 1, pp. 1-6, 2013.

[3] M. Nindi dan E. Bambang, "Pengendali Kipas Sirkulasi Udara Melalui Deteksi Suhu Udara dan Kadar Karbondioksida Berlebih," Jurnal Ilmiah Go Infotech, vol. 20, no. 1, pp. 1-8, Juni 2014.

[4] Dwinanto, I. Rosyadi, R. Lusiana, A. Wisnuadji, K. Ghatra "Pengaruh Pemaangan Exhaust Fan di Ruang Kelas 3.8 Fakultas Teknik UNTIRTA Terhadap Kenyamanan Thermal yang dihasilkan," MEKANIKA, vol. 15, no. 2, pp. 70-76, September 2016.

[5] B. Romidian, S. Iwan, S. Budi, "Pemodelan dan Pengujian Sensor TGS 2600 untuk Aplikasi Monitoring Kandunagan Gas Karbon Monoksida $\left(\mathrm{CO}^{2}\right)$," Jurnal Teknik Elektro-UNDIP, 2013.

[6] S. Ratna, D. Nataliana, Ummi A, "Sistem Monitoring Pendeteksi Kebocoran LPG Berbasis Mikrokontroler AT-Mega 16 menggunakan RF APC220," Jurnal ELKOMIKA, vol. 3, no. 2, pp. 191-211, JuliDesember 2015.

[7] S.Widodo dan D Andrian, "Prototipe Alat Pendeteksi Kebocoran Gas Beracun CO pada Mobil Menggunakan ARRAY Sensor Berbasis SMS Gateway," Journal Pseudocode, vol. 2, no. 2, pp. 98-106, September 2015.

[8] M. Isra. T, A. Muid, R. Tedy, "Pendeteksi Gas LPG dan Metana dengan Sensor Gas TGS 2610 dan TGS 2611 Berbasis Mikrokontroler AT-Mega 328P," Journal Coding, Sistem Komputer Untan, vol. 3, no. 1, pp. 11-21, 2015.

[9] K. Rida Angga, "Rancang Bangun Alat Pendeteksi dan Penanggulangan Kebocoran Gas LPG Berbasis Sensor TGS 2610," TELEKONTRAN, vol. 1, no. 1, pp. 51-58, Januari 2013.

[10] A. Heri dan M.D. Awaludin H, "Realisasi Sistem Peringatan Kebakaran Melalui Layanan SMS dan MMS," Electrical Engineering Journal, vol. 1, no. 2, pp. 131140, 2011. 